\title{
Jadwal Sholat Digital Menggunakan Metode Ephemeris Berdasarkan Titik Koordinat Smartphone
}

\author{
Anton Yudhana ${ }^{1}$, Abdul Fadlil ${ }^{2}$, Safiq Rosad ${ }^{3}$ \\ Program Studi Teknik Elektro, Universitas Ahmad Dahlan Yogyakarta ${ }^{1}$ \\ Program Studi Magister Teknik Informatika, Universitas Ahmad Dahlan Yogyakarta ${ }^{2,3}$ \\ eyudhana@ee.uad.ac.id ${ }^{1}$, fadlil@lycos.com², rhosyad@yahoo.com³
}

\begin{tabular}{l}
\hline Article Info \\
\hline History: \\
Dikirim 01 November 2018 \\
Direvisi 28 Desember 2018 \\
Diterima 17 Januari 2019
\end{tabular}

Kata Kunci:

Pemesanan

Pencarian

Sistem Informasi

Web Mobile

\begin{abstract}
Abstrak
Waktu sholat dilaksanakan ketika tanda alam muncul dan sangat terkait dengan posisi matahari di tempat masing-masing permukaan bumi. Secara astronomi, waktu sholat dapat dihitung dan akan menghasilkan jadwal sholat. Saat ini berbagai macam jadwal sholat beredar di tengah-tengah masyarakat, dengan mengacu pada koreksian daerah atau diperuntukkan kota-kota besar meskipun jadwal sholat tersebut diterapkan pada daerah yang berjauhan. penelitian ini dibuat perangkat yang dapat menampilkan jadwal waktu sholat secara elektronik, dengan menitik beratkan pada tingkat keakurasian melalui metode penentuan koordinat titik lokasi secara otomatis. Perangkat dibuat menggunakan 7-segment sebagai penampil jadwal sholat, dan diproses oleh mikrokontroller ATMEGA328. perhitungan jadwal sholat berdasarkan rumus yang digunakan oleh Departemen Agama Republik Indonesia, dengan metode ephemeris. Titik koordinat lokasi jadwal sholat ditentukan smartphone dengan memanfaatkan sensor Global Position System. Hasil pembuatan jadwal waktu sholat digital mempunyai waktu berbanding lurus dengan titik koordinat pada longitude dan latitude, sehingga hasil yang didapat mempunyai tingkat keakuratan yang tinggi.
\end{abstract}

(C) This work is licensed under a Creative Commons AttributionShareAlike 4.0 International License.

\section{Koresponden:}

Safiq Rosad

Program Studi Magister Teknik Informatika

Universitas Ahmad Dahlan Yogyakarta

Jl. Prof. DR. Soepomo Sh, Umbulharjo, Yogyakarta

Email: rhosyad@yahoo.com

\section{PENDAHULUAN}

Sholat merupakan kewajiban yang harus dilaksanakan bagi kaum muslim. Waktu sholat dilaksanakan ketika tanda alam muncul. berkaitan dengan hal ini, ibadah sholat sangat terkait dengan posisi matahari di tempat masing-masing permukaan bumi. Mengingat posisi matahari dipermukaan Bumi terlihat berbeda-beda, maka diperlukan perhitungan astronomi untuk dapat mendefinisikan masing-masing tanda-tanda awal waktu sholat. Adanya perkembangan ilmu pengetahuan dan teknologi memberikan kontribusi dalam menentukan waktu sholat. Penentuan awal waktu sholat dapat dihitung secara astronomis, tanpa melihat fenomena gerakan matahari. Artinya, umat Islam tidak lagi melaksanakan sholat dengan bersusah payah melihat saat matahari 
tergelincir, melihat panjang bayangan suatu benda, melihat matahari terbit dan terbenam, ataupun melihat hilangnya mega merah, tetapi dapat langsung melihat waktu sholat berdasarkan hasil hisab.

Secara Astronomi, waktu sholat dapat dihitung dan akan menghasilkan jadwal sholat yang yang sesuai dengan tanda-tanda alam muncul. Saat ini berbagai macam jadwal sholat beredar di tengah-tengah masyarakat, menurut Jayusman dalam penelitianya[1], Sering ditemukanya berbagai macam jadwal sholat yang beredar di tengah-tengah masyarakat. Biasanya jadwal sholat tersebut disertai dengan koreksian daerah. Koreksian daerah adalah semacam koreksi waktu berupa penambahan atau pengurangan dalam menit sebagai bentuk penyesuaian apabila sebuah jadwal sholat digunakan di daerah atau kota lain (di luar kota atau daerah peruntukannya)[2]. Namun keberadaannya diperselisihkan oleh para ahli Falak. Hal ini karena koreksian daerah tersebut hanya memperhitungkan selisih bujur tempat. Sehingga dengan koreksi daerah ini dapat dikatakan kurang tepat untuk digunakan pada tempat yang diluar dari jadwal sholat tersebut digunakan.

Menurut pendapat Darajat [3], Jadwal sholat bisa dikatakan baik dan lebih mendekati akurat mempunyai beberapa kriteria seperti, penentuan koordinat yang tepat untuk dijadikan acuan, rumus perhitungan yang digunakan dan nilai ihtiyath sebagai nilai toleransi pada hasil perhitungan. Jadi jadwal yang baik merupakan jadwal yang dihitung secara khusus untuk suatu kota, dan bukan jadwal yang merupakan hasil konversi dari daftar koreksian daerah dari perhitungan kota lain.

Pemaparan diatas merupakan bentuk permasalahan-permasalah yang dihadapi dalam penentuan waktu sholat dan penerapan didalam masyarakat. Oleh karena itu penulis dapat mengambil identifikasi masalah sebagai berikut:

1. Koreksi waktu berupa penambahan atau pengurangan sebagai bentuk penyesuaian waktu sholat untuk daerah-daerah atau kota lain yang berjauhan tidaklah akurat.

2. Dibutuhkanya sebuah media dapat menentukan waktu sholat yang dapat menyesuaikan dengan daerah atau wilayah setempat

Dari permasalahan yang dipaparkan diatas, dilakukan penelitian dengan membangun suatu perangkat yang dapat menampilkan jadwal waktu sholat secara elektronik yang sering dinamakan dengan Jadwal Sholat Digital. Titik berat pada penelitian ini adalah tingkat keakurasian dari jadwal sholat yang dihasilkan, sehingga metode yang digunakan agar mendekati tingkat keakuratan tinggi adalah metode penentuan koordinat titik lokasi secara otomatis dengan menyesuaikan dengan jadwal sholat yang akan digunakan pada daerah tersebut [4].

\section{METODE PENELITIAN}

Penelitian ini menggunakan metode dengan mencari data yang berkaitan dengan perhitungan awal waktu sholat, seperti mencari data bulan dan data matahari yang berkaitan dengan keperluan hisab. Data matahari ini merupakan kebutuhan yang paling mendasar, karena waktu sholat di tentukan oleh posisi matahari berada. data bulan dan data matahari tersaji dalam almanak ephemeris. Ephemeris Hisab Rukyat menyediakan beberapa data mengenai Matahari dan Bulan yang dapat digunakan untuk kegiatan hisab maupun rukyat, penentuan arah kiblat, waktu sholat, awal bulan qomariyah dan gerhana.

\subsection{Rumus Perhitungan Waktu Sholat}

Perhitungan waktu sholat diambil dari buku Almanak EPHEMERIS HISAB RUKYAT 2017 yang dikeluarkan Departemen Agama Republik Indonesia. Perhitungan awal waktu sholat dengan metode ephemeris dapat dilakukan dengan cara sebagai berikut :

1. Menentukan titik lokasi atau daerah yang akan dicari awal waktu sholat.

2. Menentukan tanggal, bulan dan tahun yang akan dicari awal waktu sholat.

3. Menyiapkan data yang diperlukan sesuai dengan Almanak EPHEMERIS HISAB RUKYAT, seperti:

- Deklinasi matahari $\left(\delta_{m h}\right)$.

- Equation of time (e).

4. Menentukan rumus sesuai dengan KEMENAG [5].

a) Menentukan Sudut Waktu (Cotan)

$$
\text { - Dzuhur } h_{d z u h u r}=0^{\circ}
$$


- Ashar

\begin{tabular}{|c|c|}
\hline Cotan $t$ & $=\tan [$ Lintang - Bujur $]+1$ \\
\hline - $\quad$ Maghrib & $\mathrm{h}_{\text {maghrib }}=-1^{\mathrm{o}}$ \\
\hline Isya & $\mathrm{h}_{\text {isya }}=-18^{\circ}$ \\
\hline Shubuh & $\mathrm{h}_{\text {shubuh }}=-20^{\circ}$ \\
\hline Syuruq & $\mathrm{h}_{\text {syuruq }}=-1^{\mathrm{o}}$ \\
\hline
\end{tabular}

b) Mencari Meridian Pass [6]

$M P \quad=12 j-(-e)$

c) Mencari Interpolasi

Interpolasi $=($ Bujur -105$): 15$

d) Menentukan Ikhtiyat

Ikhtiyat $=3$ menit

e) Rumus awal waktu sholat [5]

a. Dzhuhur

Awal Dzuhur $=(M P-$ Interpolasi $)+i k h t i y a t$

b. Ashar

$\operatorname{Cos} t=-\tan _{\text {lintang }} x \tan _{\text {dec }}+\sin h_{\text {asar }}: \cos$ lintang $: \cos$ dec

c. Maghrib

Awal Ashar $=(M P+C o s t)$-Interpolasi $)+i k h t i y a t$

$\operatorname{Cos} t=-\tan _{\text {lintang }} x \tan _{\text {dec }}+\sin -1^{\circ}: \cos _{\text {lintang }}: \cos$ dec

Awal Maghrib $=(M P+C o s t)$-Interpolasi $)+i k h t i y a t$

d. Isya

Cos $t=-\tan _{\text {lintang }} x \tan _{d e c}+\sin -18^{\circ}:$ coslintang $: \cos$ dec

Awal Isya $=(M P+C o s t)$-Interpolasi $)+i k h t i y a t$

e. Shubuh

$\operatorname{Cos} t=-\tan _{\text {lintang }} x \tan _{d e c}+\sin -20^{\circ}: \cos$ lintang $: \cos$ dec

Awal Shubuh $=(M P-C o s t)$-Interpolasi $)+i k h t i y a t$

f. Syuruq

$\operatorname{Cos} t=-\tan _{\text {lintang }} x \tan _{\text {dec }}+\sin -1^{\circ}: \cos _{\text {lintang }}: \cos$ dec

Awal Syuruq $=($ MP-Cos $t)$-Interpolasi $)+i k h t i y a t$

Cara diatas merupakan langkah-langkah dalam menentukan jadwal waktu sholat. Berdasarkan rumus yang didapatkan, maka dapat di buat sebuah rumus dalam bentuk perintah pemrograman, rumus tersebut ditanamkan pada sistem mikrokontroller yang berfungsi sebagai otak dalam rangkaian Jadwal Waktu Sholat Digital.

\subsection{Penampil Jadwal Sholat}

Rumus perhitungan yang menghasilkan nilai jadwal waktu sholat, diolah serta dikonversikan kedalam bahasa pemrograman dan ditanamkan pada sistem elektronika, piranti ini akan bertugas sebagai pengolah perhitungan dari rumus yang ditanamkan didalamnya sekaligus menampilkan hasilnya pada papan penampil berupa LED 7-segment. Ada beberapa perangkat modul elektronika yang menunjang suatu proses perhitungan dan proses menampilkan data pada LED 7-segment. Gambar 1 merupakan diagram blok perangkat komponen elektronika yang digunakan. 


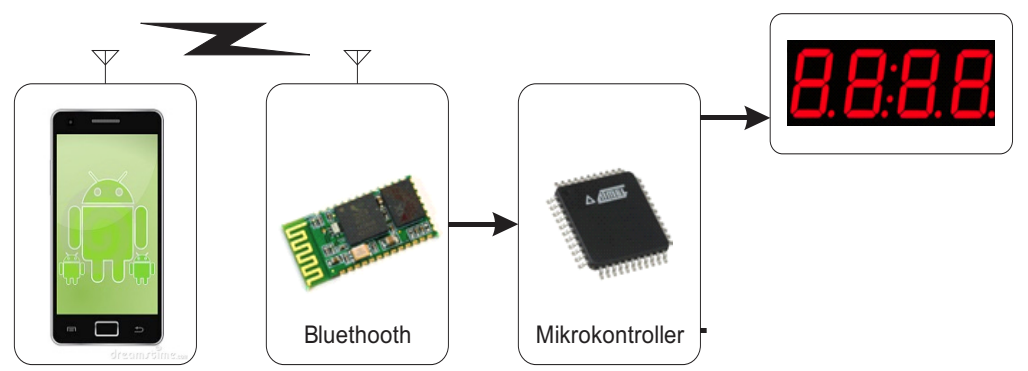

Gambar 1. Diagram Blok Rangkaian Jadwal Sholat Digital

Menurut [7], dari hasil penelitian berpendapat bahwa keseluruhan modul komponen bekerja dengan rentang tegangan standar digital, sehingga catu daya yang diperlukan berkisar antara 4,5 sampai 5,6 Volt. Beda dengan catu daya yang diperlukan oleh smartphone, karena smartphone berdiri sendiri dan bekerja tanpa ada koneksi kabel secara langsung, hanya berkomunikasi melalui frekuensi radio 2,4 GHz. Bagian perangkat elektronika yang digunakan secara terperinci sebagai berikut :

\subsubsection{Mikrokontroller}

Mikrokontroller digunakan untuk mengatur jalannya sistem. Sistem kerja mikrokontroller akan mengendalikan tampilan LED 7-segment, pengambilan data dari smartphone dan Real Time Clock. Mikrokontroller yang digunakan adalah seri ATMEGA328[8]. Sesuai dengan data sheet, Mikrokontroller ATMEGA328 [9] merupakan keluarga AVR 8 bit dan dilengkapi USART (TXD dan RXD) merupakan port komunikasi antara mikrokontroller dengan dunia luar, dalam hal ini adalah smartphone untuk mendapatkan data koordinat (GPS) dan data waktu. Selain terdapat port serial, mikrokontroller juga menyediakan 23 port paralel yang dapat digunakan sebagai media antarmuka dengan perangkat lainya seperti pada tabel 1 [10], dalam sistem Jadwal Sholat Digital terdapat kebutuhan port input output sebagai berikut:

Tabel 1. Daftar Persambungan Pin Mikrokontroller Dengan Perangkat Lain

\begin{tabular}{|l|l|c|}
\hline \multicolumn{1}{|c|}{ Modul } & Pin Mikrokontroller & Nomor PIN \\
\hline \multirow{2}{*}{ Reset } & PC6 / RESET & 1 \\
\hline \multirow{2}{*}{ Xtal } & PB6 / Xtal 1 & 7 \\
\hline \multirow{2}{*}{ RTC DS3231 } & PB7 / Xtal 2 & 8 \\
\cline { 2 - 3 } & PC4 / SDA & 27 \\
\cline { 2 - 3 } Bluethooth HC-06 & PC5 / SCK & 28 \\
\hline \multirow{3}{*}{ Modul 7-Segment 74HC595 } & PD0 / RX & 30 \\
\cline { 2 - 3 } & PD1 / TX & 31 \\
\cline { 2 - 3 } & PD4 / Data & 6 \\
\cline { 2 - 3 } & PD2 / SH & 5 \\
\hline
\end{tabular}

\subsubsection{Real Time Clock DS3231}

RTC yang dipakai adalah seri DS3231[11], berfungsi sebagai perhitungan waktu seperti Jam, Menit, Detik, Hari, Tanggal, Bulan dan Tahun. RTC DS3231 didalam rangkaian Jadwal Sholat Digital dalam penyedia data waktu dan kalender bersifat stand alone atau berdiri sendiri dalam perhitungan waktu, sehingga apabila terdapat kesimpangan waktu yang tidak sesuai, RTC tidak dapat beradaptasi dengan waktu sesungguhnya, dalam hal ini RTC diperlukan pihak luar untuk dapat menyesuaikan nilai waktu yang menyimpang. Peran antarmuka mikrokontroller disini akan memberikan masukan berupa nilai data yang sesuai, nilai yang sesuai tersebut berasal dari smartphone, karena nilai waktu dan kalender smartphone akan memperbarui secara otomatis sesuai dengan letak keberadaanya maupun secara manual dengan cara mengatur waktu pada aplikasi smartphone.

\subsubsection{Bluetooth $\mathrm{HC}-06$}

Bluetooth digunakan untuk media komunikasi data antara mikrokontroller ATMEGA328 
dengan smartphone. Bluetooth yang digunakan adalah seri HC-06 [12]. Untuk dapat berkomunikasi dengan mikrokontroller, modul Bluetooth memiliki dua pin komunikasi, yaitu TXD dan RXD [13]. Modul bluetooth HC-06 memiliki 6 buah pin, namun yang digunakan untuk berkomunikasi dengan mikrokontroler hanya 3 pin saja yaitu pin TX, VCC, dan GND[12].

\subsubsection{7-Segment}

Modul Display 7-Segment merupakan display yang tersusun dari beberapa batang lampu yang menyala membentuk tampilah angka 8 (delapan) dan dapat dikontrol bervariasi untuk dapat menampilkan nilai $0,1,2,3,4,5,6,7,8$ dan 9[14]. dimungkinkan juga menampilkan hufur a - z, akan tetapi hasil tampilan tidak sempurna. 7-segment akan menampilkan nilai digit sesuai dengan perintah yang dilakukan oleh mikrokontroller berupa tampilan Jam, Menit, Hari, Tanggal, Bulan, tahun serta jadwal waktu sholat.

\subsection{Perangkat Lunak ATMEGA328}

Mikrokontroller ATMEGA328 tidak dapat bekerja apabila perangkat lunak sebagai perintah kerja mikrokontroller tidak ditanamkan didalamnya. Mikrokontroller bekerja sebagai pengendali dari semua jalanya sistem, Sebagai perintah untuk menentukan cara kerja mikrokontroller pada Jadwal Sholat digital, dapat dilihat pada Gambar 2, yang merupakan diagram alir perangkat lunak pada mikrokontroller dalam menjalankan sistem Jadwal Sholat Digital[15].

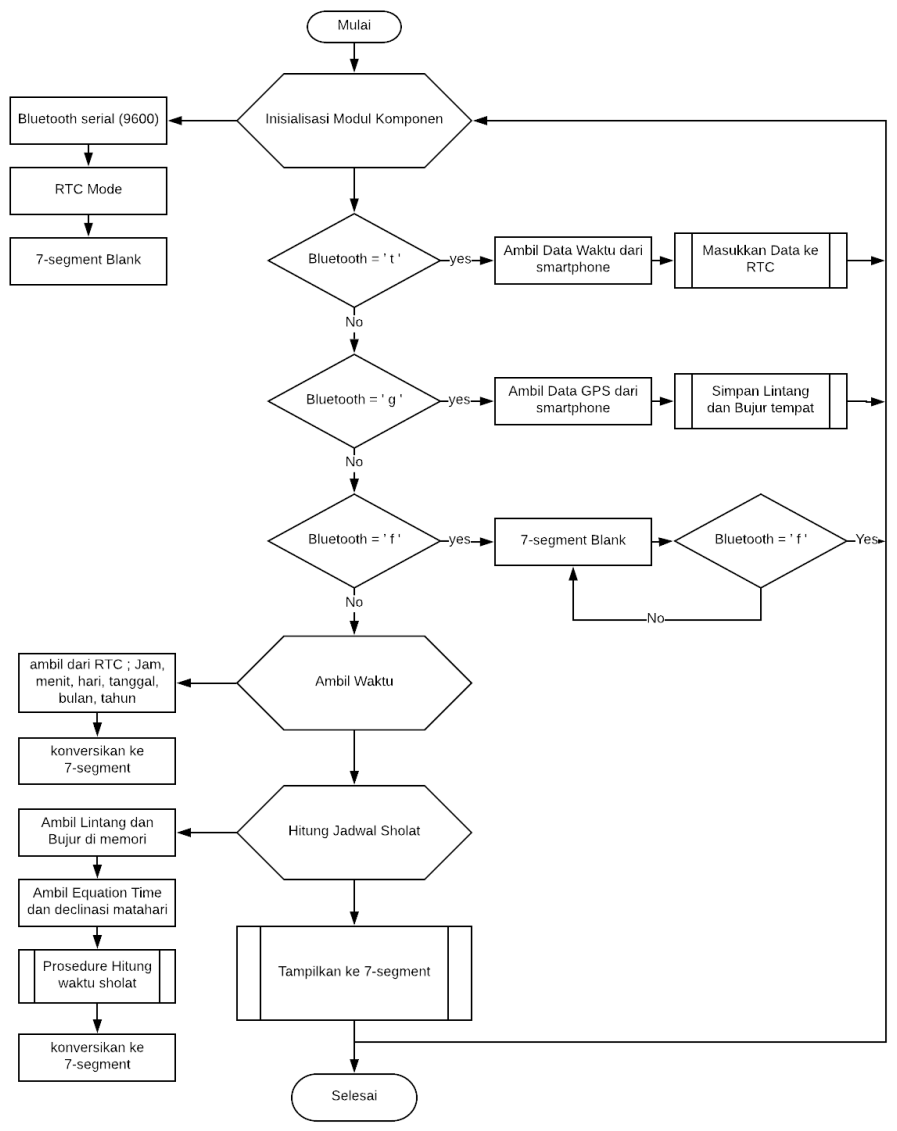

Gambar 2. Diagram Alir Perangkat Lunak ATMEGA328

Diagram alir pada Gambar 2. Perintah-perintah tersebut kemudian dikonversikan kedalam bahasa pemrograman dan selanjutnya ditanamkan pada memori program mikrokontroller ATMEGA328. Langkah dimulai dari titik 'start', yaitu menghidupkan sistem atau sistem mengalami reset (memulai perintah dari alamat 0 ). Selanjutnya sistem akan menjalankan perintahperintah seperti :

\subsubsection{Inisialisasi Modul Komponen}

Proses kerja mikrokontroller diawali dengan mengkondisikan mode kerja komponen pendukung seperti RTC, Bluetooth dan 7-segment. Bluetooth diatur pada mode kecepatan 
komunikasi dengan baudrate 9600 Bps. Perintah kecepatan baudrate merupakan perintah untuk mengaktifkan komunikasi serial, sehingga konfigurasi komunikasi serial dengan komunikasi bluetooth dalam pengaturanya kecepatan baudrate sama.

Mode kerja komponen seperti bluetooth, RTC dan 7-segment harus dipastikan bekerja dengan baik, karena menentukan perintah-perintah selanjutnya dapat berjalan dengan baik.

\subsubsection{Scanning Bluetooth}

Langkah selanjutnya adalah mendeteksi sinyal masukan dari bluetooth, sinyal masukan ini berasal dari pengiriman data smartphone, apabila smartphone mengirimkan suatu data, maka bluetooth akan menerima sinyal tersebut dan diteruskan ke mikrokontroller. Mikrokontroller dalam mode normal hanya menerima tiga kondisi masukan dengan karakter ASCII, yaitu karakter " $t$ ” , “ g" dan "f".

a. Karakter ' $t$ '

Kode ' $\mathrm{t}$ ' merupakan identifikasi dari smartphone bahwa terdapat data nilai waktu yang segera diterima oleh mikrokontroller, nilai waktu ini berupa detik, menit, jam, hari, tanggal, bulan dan tahun. Kemudian data waktu tersebut diteruskan oleh mikrokontroller menuju ke RTC DS3231 guna pembaruan data waktu.

b. Karakter 'g'

Kode ' $\mathrm{g}$ ' merupakan identifikasi dari smartphone untuk paket data GPS, atau terdapat data lintang dan bujur tempat. Data ini oleh mikrokontroller kemudian disimpan ke memori EEPROM internal ATMEGA328 agar data yang tersimpan apabila terjadi pemutusan catu daya listrik tidak akan hilang.

c. Karakter ' $\mathrm{f}$ '

Kode ' $\mathrm{f}$ ' merupakan identifikasi untuk mematikan dan menghidupkan sistem Jadwal waktu sholat.

\subsubsection{Perhitungan Waktu Sholat}

Langkah selanjutnya setelah mendapatkan data-data yang diperlukan adalah menghitung awal waktu sholat. Prosedur perhitungan dalam menentukan waktu sholat seperti diuraikan pada Sub Bab 2.1 Rumus Perhitungan Waktu Sholat. Perhitungan waktu sholat, data-data yang diperlukan adalah data koordinat bujur dan lintang tempat, data equation of time dan data deklinasi matahari. Equation of time dan deklinasi matahari berasal dari almanak Ephemeris sebagai rujukan[5]-[16]. nilai tersebut akan berubah-ubah setiap jam,tanggal dan bulannya, sehingga untuk mendapatkan nilai yang tepat, maka diperlukan nilai waktu tanggal dan bulan. lebih jelasnya, diilustrasikan pada Gambar 3. diagram flowchart: 


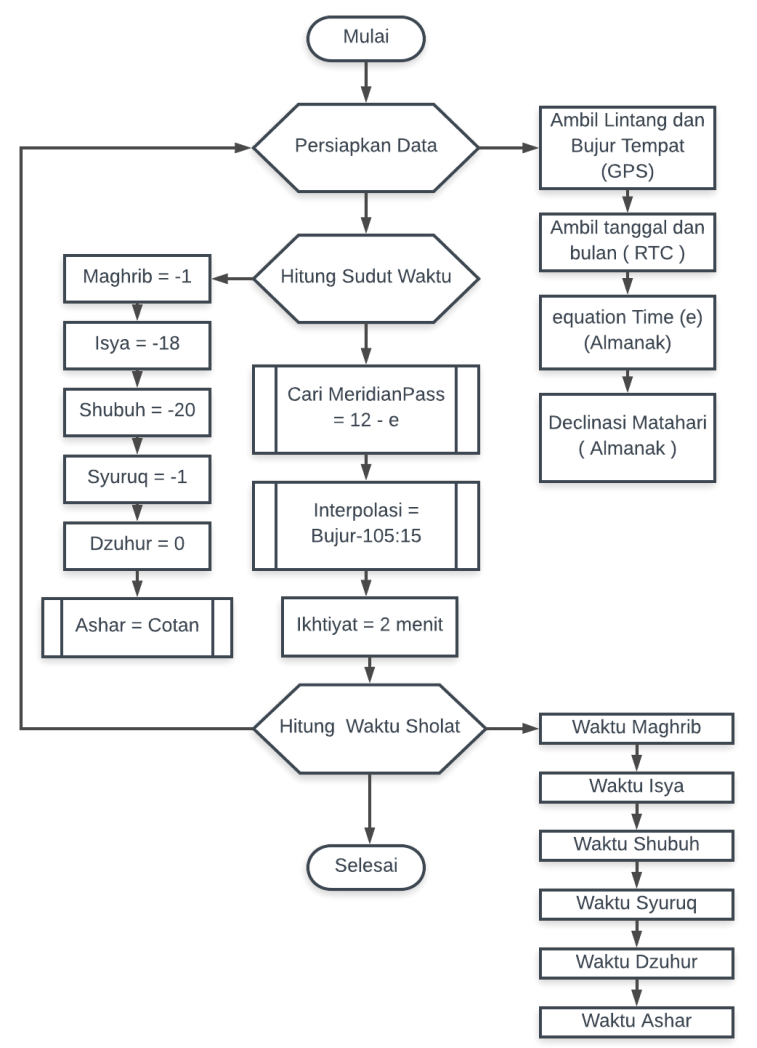

Gambar 3 Flowchart Prosedur Perhitungan Waktu Sholat

Dimulai dengan persiapan data yang akan dibutuhkan, seperti data titik koordinat. nilai data koordinat ini nantinya didapatkan dari sensor GPS yang terintegrasi dengan smartphone Android. Namun, mikrokontroller pada langkah ini hanya mengetahui bahwa data koordinat berada pada alamat memori 100 - 101 untuk bujur dan 102 - 103 untuk lintang. nilai koordinat hanya akan berubah jika terjadi pembaruan data yang berasal dari smartphone. Sehingga selama tidak ada pembaruan yang dilakukan oleh smartphone maka mikrokontroller akan mengambil data dari yang paling akhir data koordinat diperbarui atau dimasukkan.

Data equation of time dan deklinasi matahari dalam satu tahun di masukkan ke dalam sistem memori mikrokontroller yang tersusun seperti sebuah tabel, kemudian penyimpanan data tersebut diakses menggunakan metode look-Up Table [17], yaitu nilai bulan digunakan sebagai penunjuk tabel pada sisi baris, dan nilai tanggal digunakan sebagai penunjuk sisi kolom.

Data yang diperoleh seperti bujur lintang tempat, equation of time dan deklinasi matahari, kemudian digunakan untuk mencari ketinggian matahari. Khusus untuk waktu Ashar, seperti terlihat pada rumus perhitungan waktu sholat.

Setelah didapat sudut Matahari pada masing-masing waktu sholat, kemudian dicari Meridian Pass. Menurut [6] Meridian Pass (MP) adalah waktu pada saat matahari tepat di titik kulminasi atas atau tepat di meridian langit menurut waktu pertengahan, yang menurut waktu hakiki saat itu menjunjukkan tepat jam 12 siang.

Selain Meridian Pass, Untuk merubah dari waktu pertengahan menjadi waktu daerah diperlukan koreksi yang disebut interpolasi waktu interpolasi waktu ini pada dasarnya adalah waktu yang digunakan oleh matahari hayalan mulai saat berkulminasi atas di suatu tempat sampai saat ia berkulminasi atas di tempat lain.

Pada Gambar 4 diagram alir Jadwal Sholat Digital, terdapat ikhtiyat $=2$ menit. Menurut [18], Ihtiyath merupakan bentuk pengamanan pada perhitungan awal waktu salat agar seluruh kota, termasuk juga yang bermukim di sebelah baratnya dalam melaksanakan salat sudah benar-benar masuk waktunya. Hasil dari penelitia 


\subsubsection{Penampil Hasil Perhitungan}

Sampai pada proses ini, semua data yang akan ditampilkan ke 7-segment telah siap, baik berupa data waktu jam, menit, tanggal, bulan, tahun dan data jadwal sholat yang sudah berbentuk format tampilan 7-segment. Langkah paling akhir dari proses perputaran program adalah menampilkanya semua data yang telah didapat ke dalam modul 7-segment. data yang diperoleh belum dikonversikan kedalam tampilan 7-segment, sehingga pada proses ini data jadwal sholat yang didapat kemudian dikonversikan kedalam bentuk tampilan 7-segment.

\subsection{Hasil Perancangan Perangkat Keras}

Modul mikrokontroller beserta komponen-komponen pendukung seperti RTC DS3231, Bluetooth dan modul penampil 7-segment dirakit kedalam satu sistem, kemudian mikrokontroller di tanamkan perintah-perintah program seperti diuraikan diatas. Maka hasilnya adalah Jadwal Sholat Digital seperti terlihat pada gambar 4.

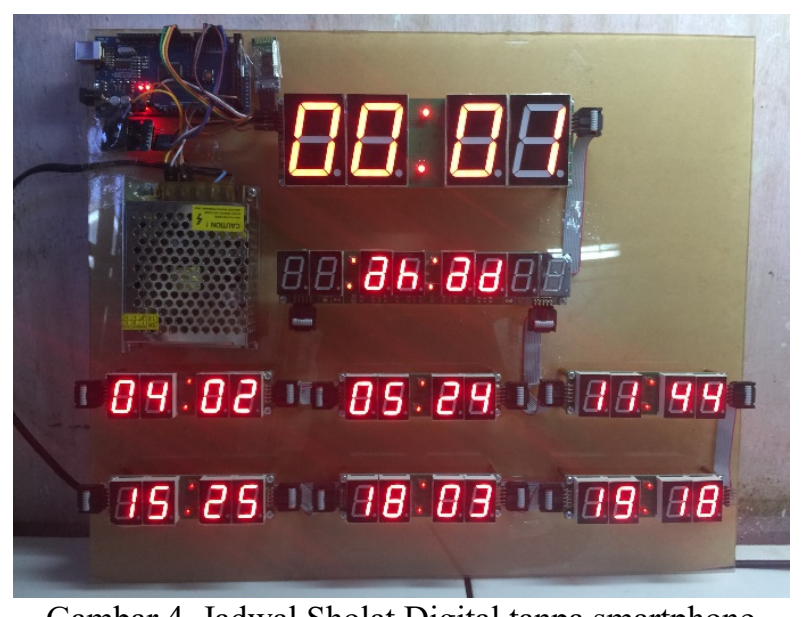

Gambar 4. Jadwal Sholat Digital tanpa smartphone

Langkah pada titik ini, sistem hanya menjalankan prosedur perintah-perintah seperti penjabaran diatas, akan tetapi mode kerja dari alat hanya bisa diatur oleh pengguna. Mode kerja dari pengguna ini dapat berupa:

- Pengaturan waktu : jam, menit, hari, tanggal, bulan dan tahun

- Pengaturan koordinat : Bujur dan lintang tempat

Maka dari itu, diperlukan antarmuka antara pengguna dengan sistem jadwal sholat. Dalam penelitian ini, digunakan smartphone sebagai sarana antarmuka antara pengguna dengan sistem Jadwal Sholat Digital.

\subsection{Aplikasi Android}

Global Positioning System pada smartphone dengan sistem operasi android menyajikan data informasi seperti: longitude, latitude, Altitude. Untuk mendapatkan data informasi dari GPS [19], diperlukan sebuah aplikasi android sebagai pengakses secara langsung terhadap GPS, untuk membuat sebuah aplikasi tersebut, diperlukan sebuah tool yang bisa untuk merancang sebuah aplikasi yang diinginkan[20]. Pada penelitian ini digunakan Appinventor sebagai tool dalam pembuatan aplikasi android untuk mengakses data GPS dan men-sinkronkan data waktu dengan jadwal sholat digital. Gambar 5 adalah sebuah diagram Use Case menggambarkan hubungan antara user dan kegiatan yang dapat dilakukan terhadap aplikasi. 


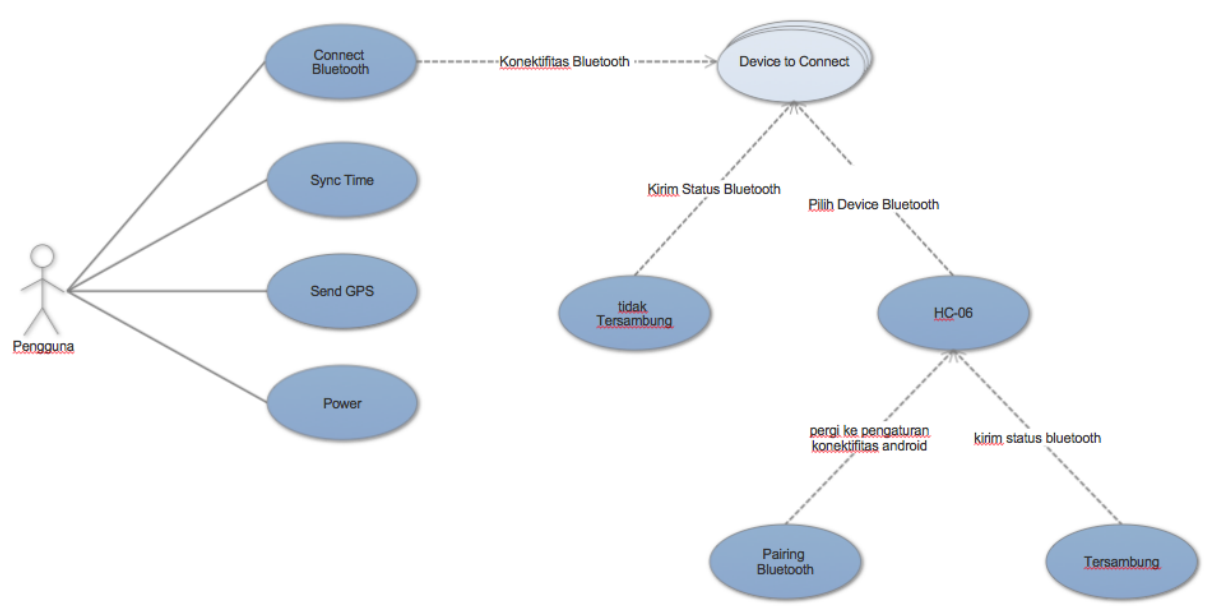

Gambar 5. Use Case Jadwal Sholat Digital

Pengguna akan diarahkan pada persambungan antara smartphone dengan mikrokontroller agar bisa berkomunikasi, sehingga mikrokontroller bisa mendapatkan data informasi yang diperlukan dari smartphone [21]. Media komunikasi ini menggunakan modul Bluetooth, sehingga langkah pertama adalah mengakses Bluetooth yang terdapat pada smartphone untuk dapat diaktifkan dan terhubung ke Bluetooth yang tersambung dengan mikrokontroller.

Pada sequence diagram (Gambar 6.) menjelaskan aliran fungsionalitas dalam penggunaan. Sebuah sequence diagram menunjukkan urutan interaksi object dan class-class yang terlibat dalam skenario dan urutan pesan yang diperlukan antara object yang dibutuhkan untuk melaksanakan fungsi skenario. Kegunaanya untuk menunjukkan rangkaian pesan yang dikirim antara object juga interaksi antara object, sesuatu yang terjadi pada titik tertentu dalam eksekusi sistem.

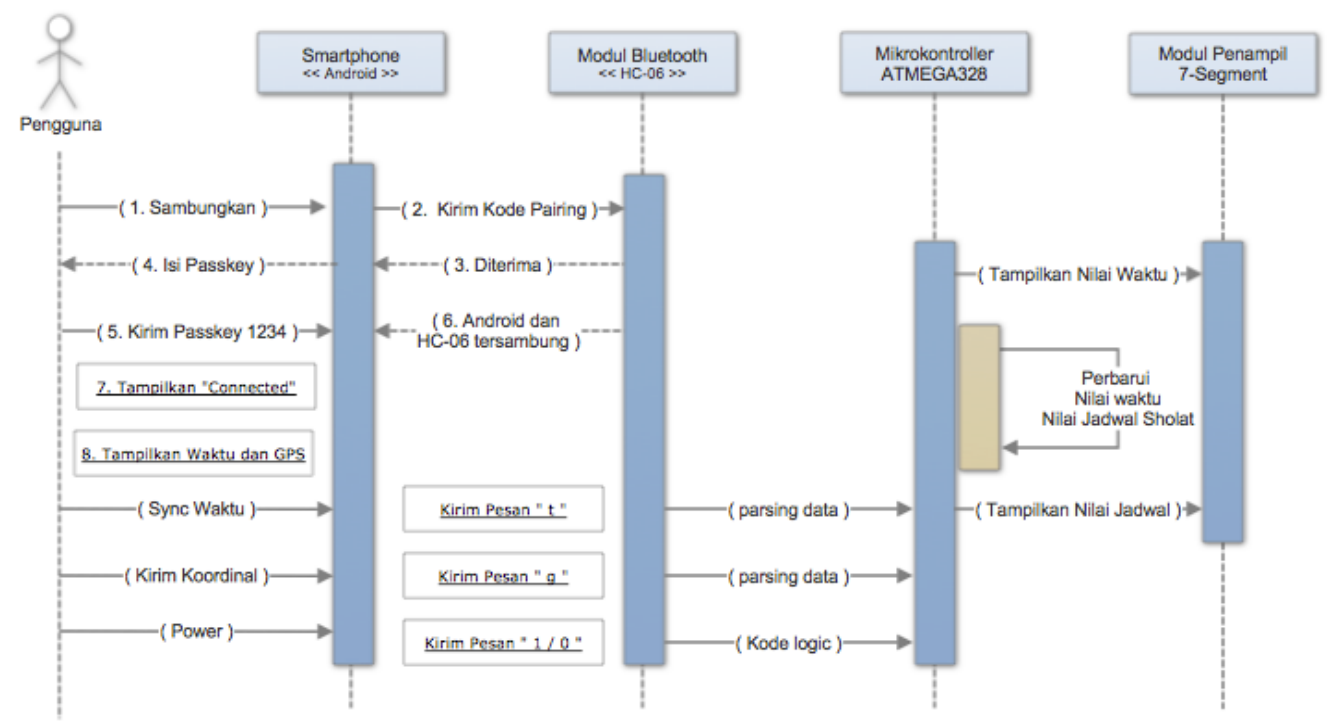

Gambar 6. Sequence Diagram Jadwal Sholat Digital berikut :

Sequence diagram Jadwal Sholat Digital dapat dijelaskan langkah-langkahnya sebagai

1. Pengguna membuka aplikasi Jadwal Sholat Digital pada smartphone, disini pengguna diminta untuk masuk kedalam menu pilihan koneksi perangkat bluetooth yang digunakan agar terhubung dengan bluetooth pada mikrokontroller.

2. Pengguna akan mengirim kode pairing agar bluetooth smartphone dengan bluetooth HC06 dapat disandingkan. 
3. Bluetooth pada smartphone dapat dikenali, dan siap untuk disandingkan

4. Pengguna memasukkan password bluetooth.

5. Dalam kondisi standar bawaan pabrik, HC-06 mempunyai password bluetooth ' 1234 '.

6. Bluetooth Android dengan Bluetooth HC-06 pada mikrokontroller tersambung.

7. Menampilkan status persambungan pada tampilan aplikasi smartphone bagian atas.

8. Menampilkan waktu yang sesuai dengan waktu pada smartphone, dilain itu menampilkan titik koordinat bujur dan lintang tempat. Untuk menampilkan bujur dan lintang tempat tidak secepat menampilkan nilai waktu pada tampilan aplikasi, karena GPS memerlukan waktu beberapa menit sampai mendapatkan sinyal yang cukup dari berbagai sinyal satelit. Maka dari itu apabila diinginkan mendapatkan data yang cepat dari GPS, maka smartphone diletakkan diluar ruangan yang tidak tertutup atap, sehingga sinyal satelit dapat diterima dengan baik.

Gambar 7 merupakan hasil aplikasi yang berfungsi sebagai antarmuka antara pengguna dengan sistem Jadwal Sholat Digital seperti ilustrasi pada sequence diagram .

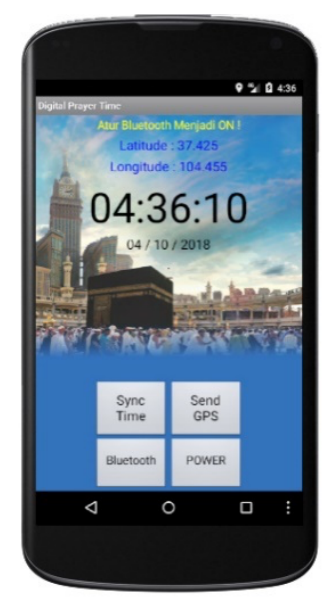

Gambar 7. Antarmuka Aplikasi Android

Tampilan utama aplikasi mempunyai empat buah tombol yang mempunyai fungsi sebagai berikut:

- Tombol Sync Time merupakan tombol untuk men-sinkronkan waktu pada android dengan waktu RTC pada mikrokontroller

- Tombol Send GPS berfungsi sebagai pengiriman data informasi latitude dan longitude kepada mikrokontroller

- Tombol Bluetooth pengaturan konektifitas smartphone dengan modul Bluetooth HC-06 pada mikrokontroller

- Tombol POWER sebagai tombol power menghidupkan atau mematikan perangkat jadwal waktu sholat digital.

Setiap proses kejadian yang dilakukan smartphone dalam berkomunikasi dengan mikrokontroller, akan di tampilkan status yang terjadi pada tampilan bagian paling atas.

\section{HASIL DAN PEMBAHASAN}

Perakitan dari setiap modul yang digunakan seperti mikrokontroller ATMEGA328, RTC DS3231, modul 7-segment dan modul Bluetooth, disusun sesuai dengan fungsinya masing masing, sehingga didapatkan rangkaian jadwal waktu sholat digital yang dapat dilihat pada Gambar 8 . 


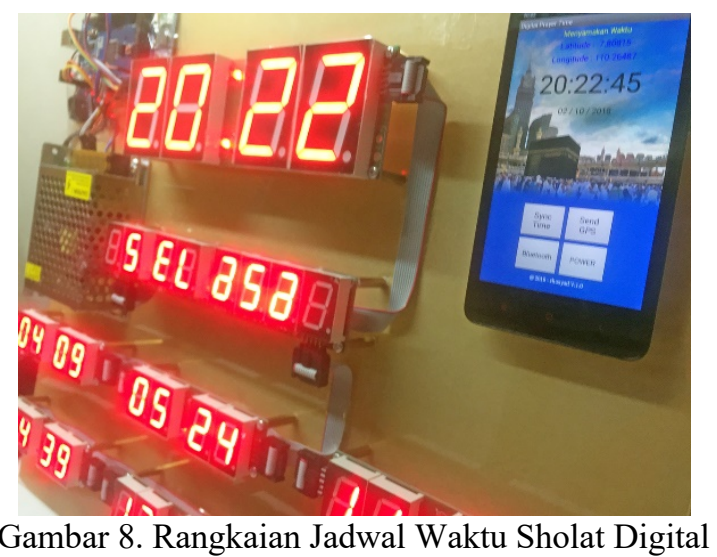

Jadwal Sholat digital pada kondisi awal sudah bisa menampilkan waktu seperti jam, menit, hari, tanggal, bulan dan tahun sesuai dengan data yang tersedia pada RTC DS3231. Sedangkan tampilan jadwal sudah tertampil untuk awal waktu sholat shubuh, syuruq, dzuhur, ashar, maghrib dan isya.

\subsection{Pengujian Jadwal Sholat Digital}

Koordinat geografis suatu kota memiliki kedudukan yang penting dalam perhitungan waktu sholat dan penentuan waktu ihtiyath. Koordinat georafis, dalam hal ini bujur dan lintang yang digunakan akan berpengaruh terhadap hasil perhitungan awal waktu sholat suatu kota. Maka dari itu, penelitian ini dilakukan perbandingan hasil akurasi waktu jadwal sholat digital yang dibuat dengan jadwal sholat digital yang telah digunakan oleh masyarakat, terutama pada masjid yang menggunakan jadwal sholat digital sebagai acuan dalam memasuki waktu sholat.

Pengambilan data perbandingan waktu sholat dilakukan dengan cara mengambil sampel jadwal sholat digital pada masjid yang berada pada wilayah provinsi Yogyakarta. Dengan melihat letak geografis Yogyakarta, seperti terlihat pada Gambar 9.

Pengambilan sampel pada peta ditunjukkan dengan logo

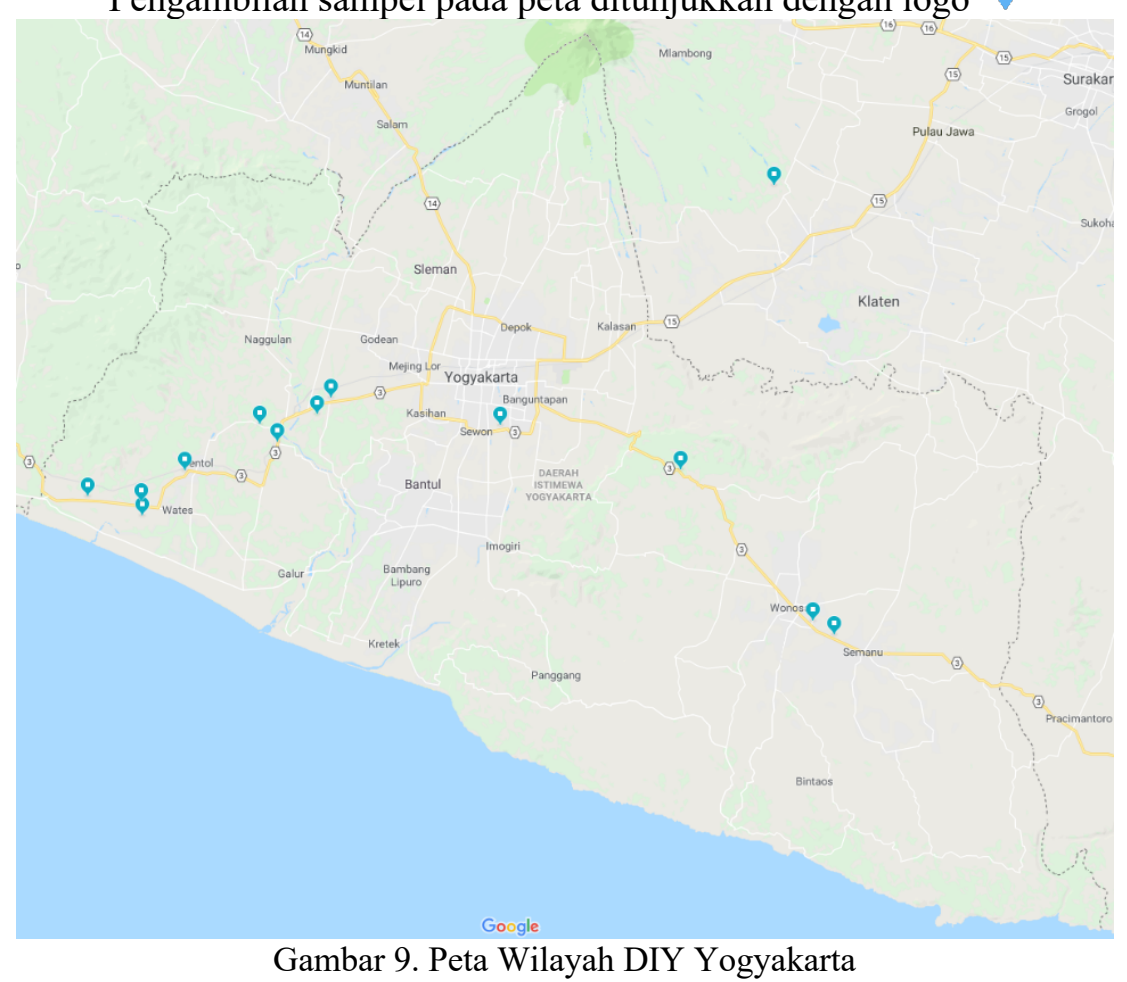


Daerah yang ada pada sisi barat Yogyakarta adalah Kabupaten Kulon Progo, diambil sampel pada Kecamatan Temon. untuk sampel pada daerah sisi timur adalah Kabupaten Gunung Kidul pada Kecamatan Semanu. Untuk mendapatkan titik koordinat suatu wilayah, digunakan sensor GPS. Sensor GPS pada jadwal sholat digital sudah teintegrasi dengan smartphone. Gambar 10. Merupakan pengujian dengan perbandingan Jadwal Sholat Digital (Digital Prayer Time) yang mengacu pada titik koordinat lokasi masjid yang di hitung waktu sholatnya (yang dibuat) dengan waktu sholat yang telah digunakan pada setiap masjid [22]. Pengujian dilakukan pada tanggal 13 Oktober 2018.

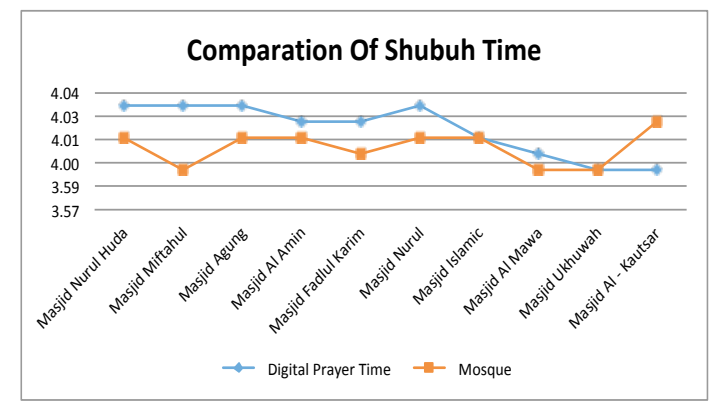

(a)

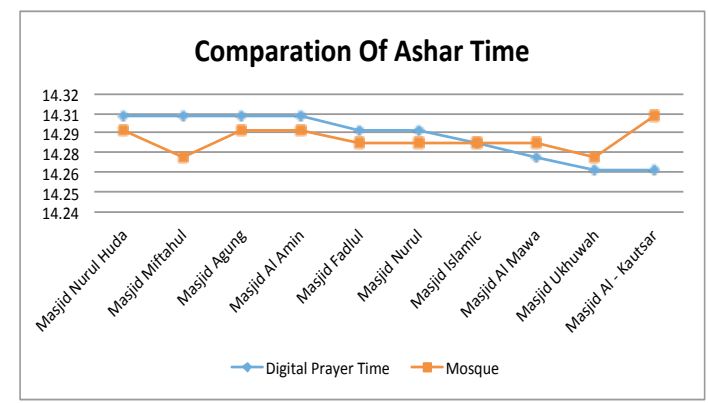

(c)

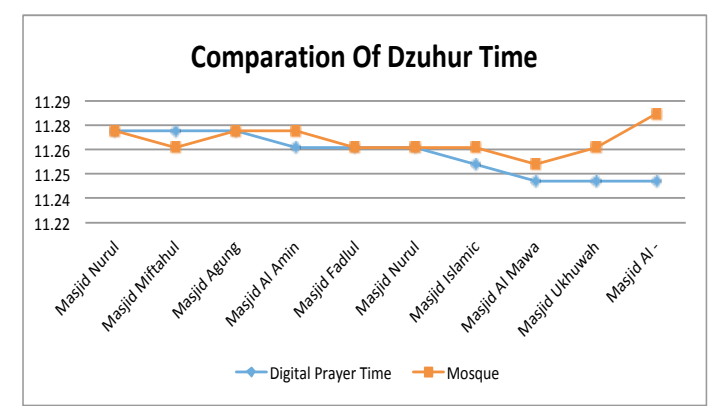

(b)

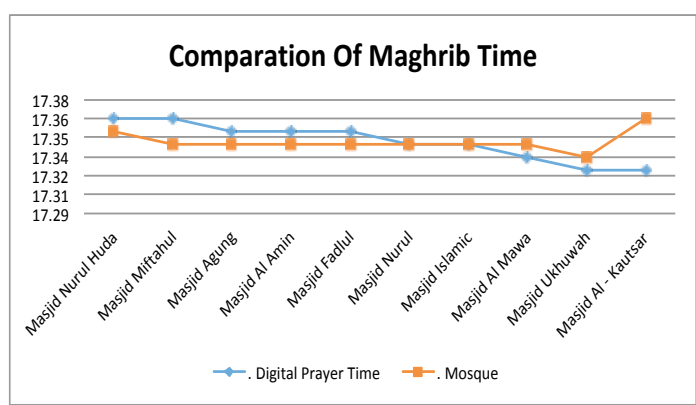

(d)

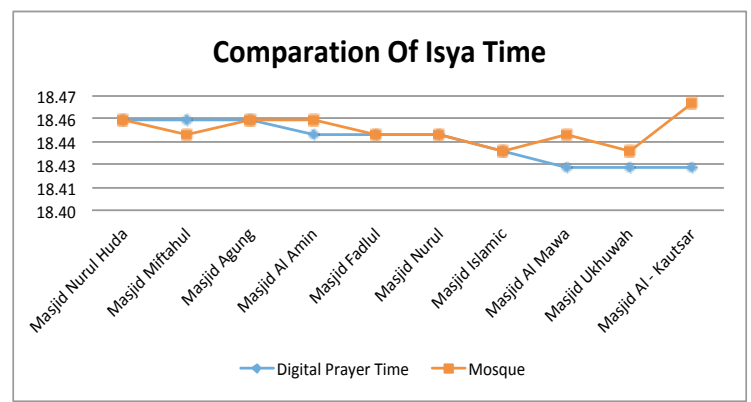

(e)

Gambar 10. Grafik Perbandingan Jadwal Sholat Digital (a) Waktu Sholat Shubuh, (b) Waktu Sholat Dzuhur, (c) Waktu Sholat Ashar, (d) Waktu Sholat Maghrib, (e) Waktu Sholat Isya

Dari Gambar 10 terlihat bahwa, jadwal sholat pada garis warna biru (Jadwal Sholat Digital yang dibuat) mempunyai waktu berbanding lurus dengan titik koordinat pada longitude dan latitude, hal ini menunjukkan hasil perhitungan waktu sholat yang tertampil berdasarkan letak posisi Jadwal Waktu Sholat Digital tersebut berada. Apabila digeser ke lokasi yang berlainan, maka waktu sholat juga akan menyesuaikan.

Sesuai dengan data yang diperoleh dari setiap sampel masjid yang diambil (garis warna orange), hampir terdapat kesamaan waktu sholat dari setiap masjid. hal ini dapat dilihat dari Gambar 10, yaitu pola garis orange dari setiap waktu mempunyai kesamaan, meskipun tempat 
saling berjauhan. Apabila terdapat selisih waktu, dimungkinkan berlainan pabrikan pembuat jadwal sholat digital. Beda pabrikan pembuat jadwal sholat terjadi perbedaan waktu, hal ini dimungkinkan referensi yang diambil juga berbeda.

Pertimbangan yang paling mendasar hasil dari Gambar 10 adalah wilayah DIY Yogyakarta bagian Barat yaitu Masjid Nurul Huda, Kecamatan temon kulonprogo, dengan wilayah DIY Yogyakarta Bagian timur yaitu Masjid Al-Kautsar, Kecamatan Semanu, Gunung kidul, mempunyai waktu sholat yang sama. Sedangkan apabila di tarik garis lurus, antara kedua masjid mempunyai jarak 62 KM. Jika dibandingkan waktu sholat pada masjid dengan Jadwal Sholat Digital yang dibuat, waktu sholat yang tertampil pada masjid apabila sudah menambahkan factor ikhtiyat dengan nilai 2 atau 3 menit, maka sifat dari kehati-hatian perhitungan waktu sholat sudah tidak terpenuhi lagi[1].

\section{KESIMPULAN}

Penggunaan smartphone menjadikan perangkat Jadwal Sholat Digital lebih sedikit komponen elektronika yang digunakan. Karena GPS dan fungsi Navigasi pada applikasi sudah dapat mengendalikan mode kerja Jadwal Waktu Sholat Digital.

Appinventori bekerja secara sederhana dan mudah dalam pembuatan sebuah aplikasi android tanpa harus menguasai bahasa pemrograman. Dengan meletakkan layout dari masing-masing fungsi seperti Bluetooth, GPS, Pewaktu dan media antarmuka pengguna.

Perhitungan waktu sholat yang mengacu pada titik koordinat lokasi, menjadikan waktu sholat berbanding lurus dengan titik koordinat pada longitude dan latitude, sehingga hasil yang didapat mempunyai tingkat keakuratan yang tinggi.

\section{UCAPAN TERIMA KASIH}

Penelitian ini penulis dedikasikan untuk Magister Teknik Informatika Universitas Ahmad Dahlan Yogyakarta, yang telah menyediakan sarana dan prasarana dalam penelitian.

\section{DAFTAR PUSTAKA}

[1] Jayusman, "Akurasi Jadwal Salat Arius Syaikhi Payakumbuh Sebagai Panduan Waktu Salat Bagi Masyarakat Provinsi Lampung," Al-ADALAH, vol. XII, no. 2, p. 381, 2014.

[2] Jayusman, "Jadwal Sholat Hasil Konversi Koreksian Daerah : Antara Kepentingan Efisiensi dan Akurasi," J. Pemikir. Huk. dan Huk. Islam, vol. 5, no. 2, 2014.

[3] A. Fadlil, Sunardi, and N. Darajat, Muhammad, "Sistem Informasi Arah Kiblat Dan Jadwal Waktu Shalat Di Kota-Kota Besar Di Indonesia," in Prosiding Interdisciplinary Postgraduate Student Conference 1, 2016, pp. 104-109.

[4] W. Nurwicaksana, S. Riskitasari, M. Pamenang, L. Widigyo, and S. Adhisuwignjo, "Alat Pengingat Waktu Sholat Di Masjid Berbasis Raspberry Pi," Pros. SNATIF Ke-4, vol. 4, pp. 111-118, 2017.

[5] Kementerian Agama Republik Indonesia, "Ephemeris Hisab Rukyat 2017," Jakarta, 2017, p. 420.

[6] Kementerian Agama Republik Indonesia, Buku Saku Hisab Rukyat. 2013.

[7] A. Yudhana, A. Fadlil, and S. Rosad, "Rancang Bangun Jadwal Sholat Digital Terkendali Android," SEMANTIKOM, pp. 25-32, 2017.

[8] A. Yudhana and S. Pratama, Usallil, "Otomatisasi Sistem Penyiram dan Pemupukan Tanaman Berbasis Mikrokontroller ATMEGA8535," in Seminar Nasional Serba Informatika, 2017, vol. 1, no. 1, pp. 96-101.

[9] Atmel, “ATmega328," 2016.

[10] E. Sutinah, "Sistem Informasi Penjadwalan Waktu Sholat Berbasis Mikrokontroler ATMega16," Informatics Educ. Prof., vol. 1, no. 1, p. 2014, 2014.

[11] Dallas Semiconductor, "Extremely Accurate I2C-Integrated RTC," 2005.

[12] A. Zainuri, U. Wibawa, and E. Maulana, "Implementasi Bluetooth HC - 05 untuk Memperbarui Informasi Pada Perangkat Running Text Berbasis Android," Eeccis, vol. 9, no. 2, pp. 164-165, 2015. 
[13] F. Silvia, E. Haritman, and Y. Muladi, "Rancang Bangun Akses Kontrol Pintu Gerbang Berbasis Arduino Dan Android," Electrans, vol. 13, no. 1, pp. 1-10, 2014.

[14] T. Sutikno, A. Yudhana, and D. Siprian, "Pengaturan Sakelar Pada Acara Cepat Tepat Berbasis Mikrokontroler At89C2051," TELKOMNIKA, vol. 4, no. 3, pp. 185-192, 2006.

[15] R. Didik and M. Wahyudi, "Rancang Bangun Perangkat Lunak Penentu Arah Kiblat, Penghitung Waktu Sholat dan Konversi Kalender Hijriyyah Berbasis Smartphone Android," J. Tek. Inform. FST UIN Sunan Kalijaga, vol. 5, no. 1, pp. 78-85, 2015.

[16] J. Lasagabaster and F. Diggelen, "Method And System For Mobile Device Based Gnss Position Computation Without Ephemeris Data," vol. 1, no. 19, 2014.

[17] Muchlas, Sunardi, and T. Antoro, "Pengendalian kecepatan motor dc dengan metode look up table berbasis mikrokontroler at89c51," Telkomnika, vol. 4, no. 1, pp. 1-10, 2006.

[18] T. Putra, Nanda, "Problematika Waktu Ihtiyath dalam Pembuatan Jadwal Shalat," J. Huk. dan Syariah, vol. 3, no. 1, pp. 92-105, 2012.

[19] C. Specht and P. Dabrowski, "Runaway PRN11 GPS satellite," Environ. Eng., no. April, pp. 27-28, 2017.

[20] A. Yudhana, S. Sunardi, and A. Ikrom, "Aplikasi Android Untuk Monitoring Kualitas Lahan Pertanian," Pros. SNST ke-9, pp. 45-50, 2018.

[21] A. Bennet, Thamilvalluvan, H. Priya, Bhavani, and Shalini, "Android Based Home Automation And Anergy Conservation," Int. J. Smart Sens. Intell. Syst. Spec. Issue, no. September, 2017.

[22] Y. Yudhanto, "Perbandingan Hasil Rumus Jadwal Shalat dengan Implementasi Sistem Operasi Android," in KNS\&I Bali, 2014, vol. 1979-9845, no. August. 